\title{
Caffeine impairs gastrointestinal function in newborn rats
}

\author{
Christopher Welsh', Jingyi Pan' and Jaques Belik ${ }^{1,2}$
}

BACKGROUND: Feeding intolerance is commonly documented in premature infants. Caffeine is routinely utilized for apnea of prematurity treatment and known to reduce the lower esophageal sphincter (LES) muscle tone, but the caffeine effect on the newborn gastrointestinal function is unknown. We hypothesized that caffeine impairs esophageal and gastrointestinal motor function. As such, we investigated the drug effect on the tissue's mechanical properties and the newborn rat's in vivo gastric emptying rate.

METHODS: The effects of caffeine on LES, gastric fundal and antrum, as well as ileal and colonic muscle force potential and relaxation response, were measured in newborn and adult rats. The caffeine-induced (10 mg/kg i.p.) newborn gastric emptying rate changes were evaluated following $3 \mathrm{~h}$ of fasting.

RESULTS: Caffeine relaxed the precontracted LES and fundal muscle $(P<0.01)$, reduced the gastric and intestinal muscle contraction $(P<0.01)$, and delayed the pups' gastric emptying time $(P<0.01)$. The caffeine-induced muscle relaxant effect was independent of age and mediated via ryanodine receptors.

CONCLUSION: Caffeine administration to newborn rats at a dose comparable to the one therapeutically used for preterm neonates impairs LES and gastrointestinal motor function. Further clinical investigation on the possible contribution of caffeine to neonatal feeding intolerance is warranted.

C affeine effectively treats apnea of prematurity and is one of the most common drugs utilized in neonates (1). The drug belongs to the methylxanthine family and stimulates breathing via its effector role in the brain medullary respiratory center $(2-4)$. The respiratory stimulation properties of the drug depend on the central nervous system adenosine inhibitory effect $(5,6)$. This adenosine receptor inhibitory function also allows caffeine to play an important role in the regulation of other neurotransmitter pathways involving dopamine, acetylcholine, and serotonin (7). Similarly, gastrointestinal motor function is regulated via adenosine-dependent neurotransmitters (8). Acetylcholine, and to a lesser extent dopamine and serotonin, stimulates gastrointestinal muscle contraction and thus modulates its motor function (9).

In preterm neonates, methylxanthines exacerbate the gastroesophageal reflux commonly documented in these infants, because of their negative effect on the lower esophageal sphincter (LES) muscle tone $(10,11)$. Whether methylxanthines have a similar effect on other sphincter and non-sphincter gastrointestinal muscles has not been adequately evaluated.

The caffeine effect on different smooth muscle types has been extensively studied mostly with a view to address the mechanism responsible for $\mathrm{Ca}^{2+}$ sparks and spontaneous transient outward currents induced by large-conductance $\mathrm{Ca}^{2+}$-activated $\mathrm{K}^{+}$channels (12-14). Such data indicate that in adult animals caffeine has a relaxant effect in different smooth muscle types including the gastrointestinal motor fibers (15-18), via an increase in intracellular cyclic 3',5'-adenosine mono-phosphate levels (19-21), calmodulin kinase II activation (15), and actin depolymerization (22). However, little is known about the caffeine effect on the newborn gastrointestinal function.

Caffeine is commonly prescribed to preterm neonates in the first days of life while enteral nutrition is being initiated or advanced (23). Feeding intolerance is a common issue in preterm infants, and the factors accounting for their reduced gastrointestinal transit time are poorly understood. The effect of caffeine on the newborn gastrointestinal motor function and transit time has not been previously evaluated and was the main goal of this study. We hypothesized that caffeine not only has an LES muscle relaxant effect but also delays the gastric emptying time in newborn rats and reduces gastrointestinal muscle tone.

\section{RESULTS}

Caffeine Relaxes the Lower Esophageal Sphincter (LES)

The caffeine effect on the newborn rat LES muscle tone was evaluated first. For this, the LES muscle strips were either carbachol-stimulated in the presence of caffeine to measure its effect on the force potential, or precontracted with this muscarinic agonist, and the caffeine dose-response relaxant effect was evaluated. As shown in Figure 1a, caffeine significantly $(P<0.01)$ decreased the carbachol-induced LES muscle contraction by $30 \%$. In precontracted LES muscle strips, caffeine induced a concentration-dependent response, resulting in over $50 \%$ relaxation at $10^{-3} \mathrm{M}$ (Figure $1 \mathrm{~b}$ ).

\section{Caffeine Reduces Gastric and Intestinal Muscle Tone}

The gastric and intestinal carbachol-induced muscle contraction in the absence and presence of caffeine was assessed further. Caffeine significantly decreased gastric fundal and 
a

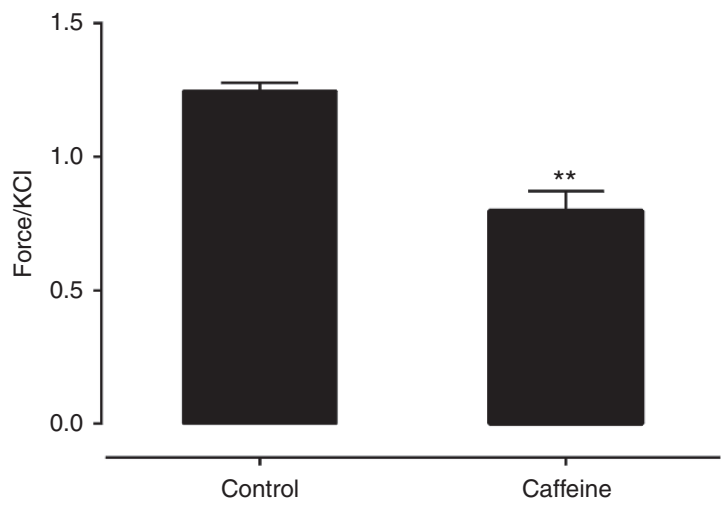

b

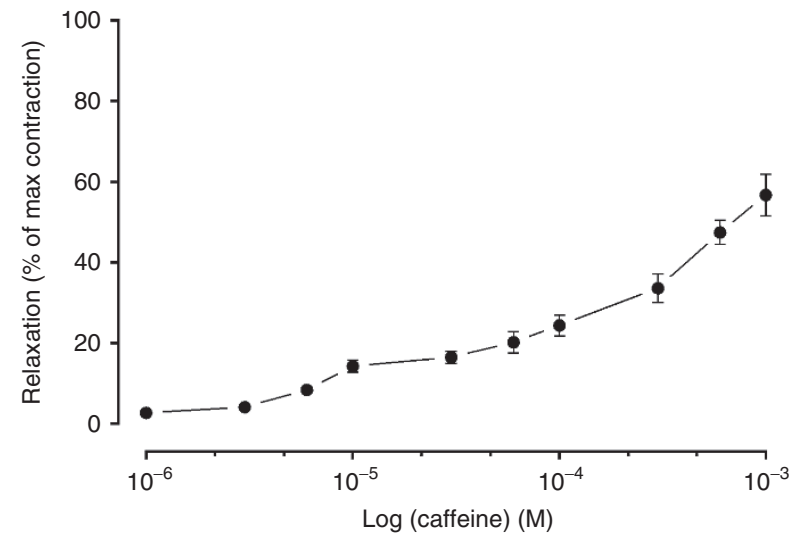

Figure 1. Caffeine relaxes the lower esophageal sphincter (LES). (a) Newborn LES carbachol-induced force response $\left(10^{-4} \mathrm{M}\right)$ normalized to $128-\mathrm{mmol} / \mathrm{l} \mathrm{KCl}$-induced contraction in the absence and presence $(N=6)$ of caffeine $\left(10^{-3} \mathrm{M}\right)$. (b) Caffeine-induced relaxant dose response in carbachol precontracted newborn LES tissue $(N=6) .{ }^{* *} P<0.01$ as compared with control values by paired Student's $t$-test.

antrum muscle tone by 25 and 60\%, respectively (Figure 2a; $P<0.01)$. An even greater effect was noted in intestinal tissue where caffeine decreased both the ileal and descending colon smooth muscle contraction response to carbachol stimulation by $80 \%$ (Figure $2 \mathrm{~b} ; P<0.01$ ).

\section{Caffeine Reduces Fundic Muscle Tone Via a Ryanodine Receptor- Dependent Mechanism}

The newborn gastric muscle relaxation dose response to caffeine was evaluated in fundal strips precontracted with carbachol. As shown in Figure 3a, caffeine significantly decreased the fundal muscle tone, resulting in almost $75 \%$ relaxation at $10^{-3} \mathrm{M}$. The antral smooth muscle relaxation could not be ascertained due to its inherent phasic activity.

In order to evaluate as to whether the caffeine relaxant effect on the gastric fundic muscle is mediated via ryanodine receptors, we proceeded to test the effect of ryanodine on the caffeine response. Others have previously shown that ryanodine partially reverses the caffeine relaxant effect in adult rat fundic muscle (15). As shown in Figure 3b, ryanodine reversed the caffeine-induced relaxation by $36 \%(P<0.01)$, an inhibitory effect of similar proportions to the one previously reported in adult rat tissue (15).
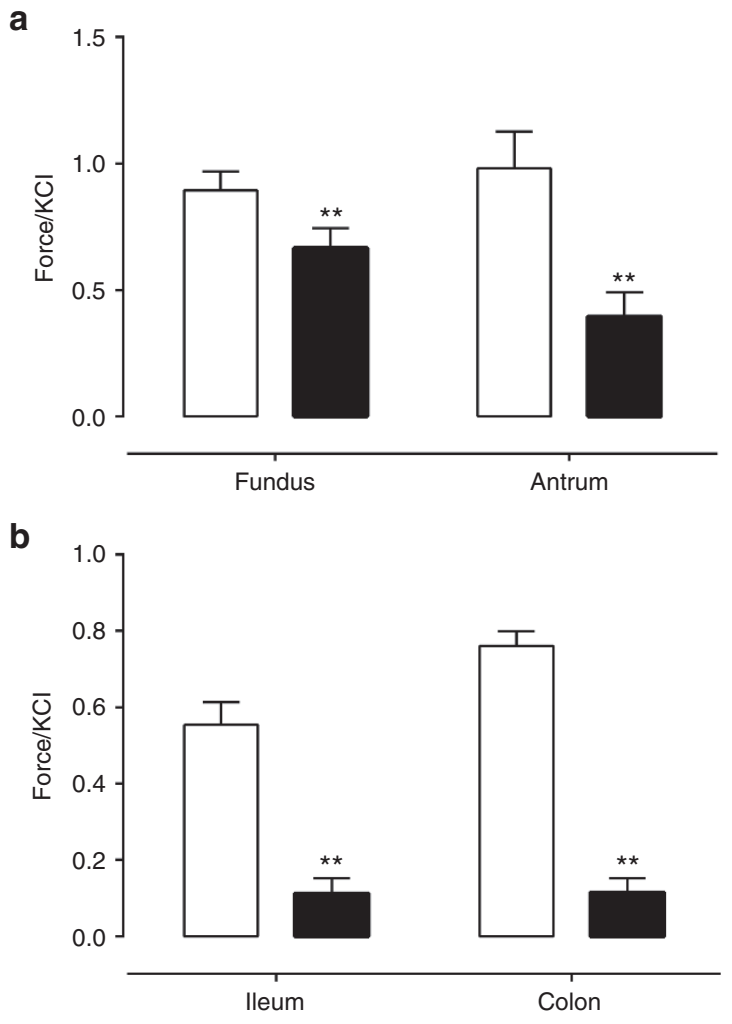

Figure 2. Caffeine reduces gastric and intestinal muscle tone. (a) Newborn fundic and antral smooth muscle carbachol-induced force $\left(10^{-4} \mathrm{M}\right)$ normalized to $128-\mathrm{mmol} / \mathrm{I} \mathrm{KCl}$-induced contraction, in the absence (open bars; $N=7$ and 5 , respectively) and presence (solid bars; $N=7$ and 5, respectively) of caffeine $\left(10^{-3} \mathrm{M}\right)$. (b) Newborn ileal and descending colon smooth muscle carbachol-induced force $\left(10^{-4} \mathrm{M}\right)$ normalized to $128-\mathrm{mmol} / \mathrm{I} \mathrm{KCl-induced} \mathrm{contraction} \mathrm{in} \mathrm{the} \mathrm{absence} \mathrm{(open}$ bars; $N=8$ and 10 , respectively) and presence (solid bars; $N=8$ and 10 , respectively) of caffeine $\left(10^{-3} \mathrm{M}\right) .{ }^{* *} P<0.01$ compared with control values by paired Student's $t$-test.

\section{Caffeine Delays Newborn Gastric Emptying}

We proceeded to evaluate whether caffeine has an in vivo effect on gastric emptying rate. Compared with saline-injected animals, caffeine significantly $(P<0.01)$ increased gastric emptying time in newborn rats, as evidenced by the greater stomach content, following fasting for $3 \mathrm{~h}$ (Figure 4 ). The in vivo caffeine effect on intestinal transit time was not evaluated, since there are no suitable techniques to assess this parameter in the newborn rodent.

\section{Caffeine Relaxant Comparative Effect in the Adult Rat}

Finally, we measured the caffeine effect on the adult rat esophageal and gastrointestinal muscle tone. As shown in Figure 5, caffeine induced a $50-60 \%$ reduction $(P<0.01)$ in the carbachol-induced force in all tested tissues.

\section{DISCUSSION}

In this study, we documented that caffeine significantly reduces LES, gastric, and bowel smooth muscle tone, and induces delayed gastric emptying in newborn rats. The caffeine effect is not age-dependent such that this compound equally reduces 
a

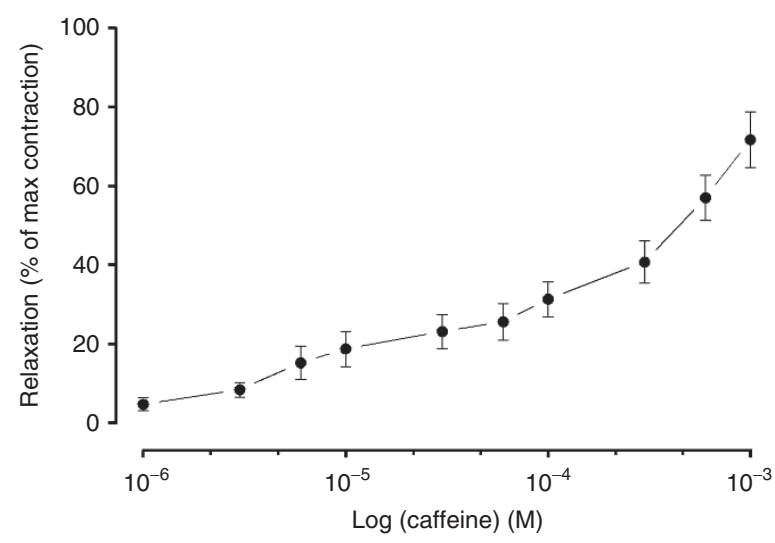

b

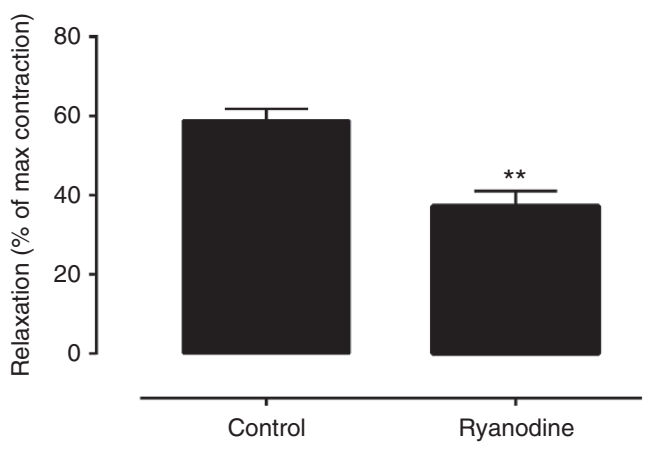

Figure 3. Caffeine reduces fundic muscle tone via ryanodine sensitive mechanism. (a) Caffeine relaxant dose response of newborn fundic muscle precontracted with carbachol $(N=6)$. (b) Effect of ryanodine $\left(10^{-5} \mathrm{M}\right)$ on the caffeine-induced $\left(10^{-3} \mathrm{M}\right)$ relaxant response of newborn fundic muscle precontracted with carbachol $\left(10^{-4} \mathrm{M}\right) .{ }^{*} P<0.01$ as compared with control values by paired Student's $t$-test.

the esophageal and gastrointestinal muscle tone of adult rats. The mechanism responsible for the caffeine-induced gastrointestinal muscle tone in the newborn is mediated via smooth muscle cell ryanodine receptors, as previously shown in adult rat tissue (15). To the best of our knowledge, this is the first English literature report addressing the effect of caffeine on the gastrointestinal muscle tone early in life.

Caffeine is the most prescribed drug (1) in neonates and proven to be therapeutically beneficial for apnea of prematurity (24), prevention of bronchopulmonary dysplasia, and neuroprotection (25). Theophylline, another methylxanthine, is equally as effective as a respiratory stimulant in neonates, but its use is associated with more cardiovascular and central nervous system side effects, as compared with caffeine $(4,26)$.

Although the coffee ingestion effect on the gastrointestinal motor and LES sphincter tone in adults is controversial (27), methylxanthines are known to enhance gastroesophageal reflux in preterm infants (11). In adult mice, caffeine decreases the fundal smooth muscle basal tone to $\sim 85 \%$ of the response obtained with a nitric oxide donor compound (15). Caffeine also decreases the basal tone and amplitude of phasic smooth muscle contractions in the gastric antrum of adult mice (16). Yet, the gastrointestinal effects of caffeine have not been studied in neonates. This represents a significant knowledge gap

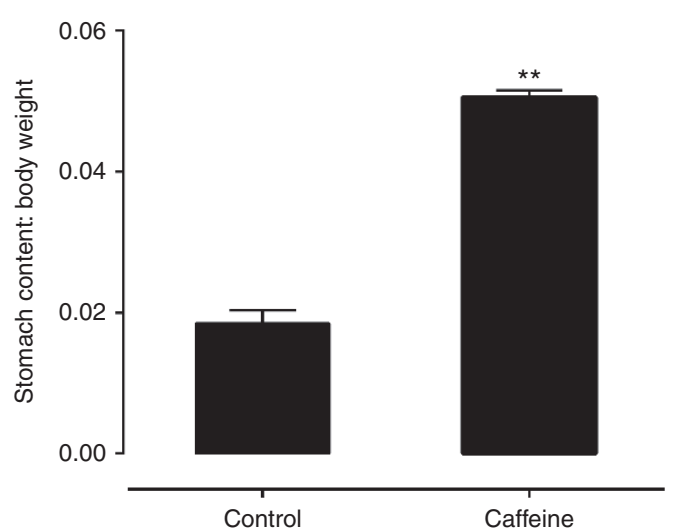

Figure 4. In vivo measurement of gastric emptying time. Stomach content: body weight ratio following caffeine $(10 \mathrm{mg} / \mathrm{kg}$ i.p.) or saline (control, similar volume to caffeine group i.p.) in newborn animals ( $N=4$ for each group). ${ }^{*} P<0.01$ as compared with control group by unpaired Student's $t$-test.

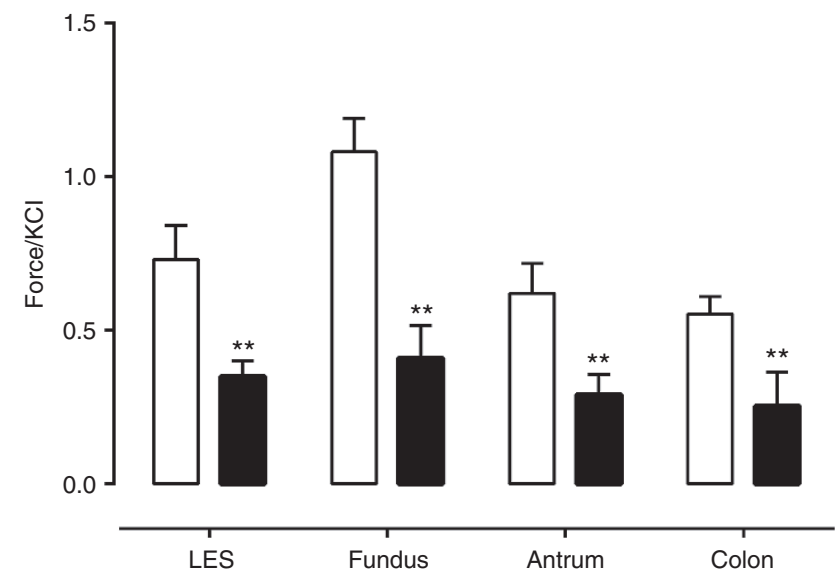

Figure 5. Caffeine reduces LES, gastric, and intestinal muscle tone in adult rat. Adult lower esophageal sphincter (LES; $N=10)$, fundic $(N=9)$ antral $(N=10)$, and colon $(N=5)$ subjected to carbachol-induced $\left(10^{-4} \mathrm{M}\right)$ muscle contraction normalized to $128-\mathrm{mmol} / \mathrm{KCC}$-induced contraction, in the absence (open bars) and presence (solid bars) of caffeine $\left(10^{-3} \mathrm{M}\right)$. ${ }^{* *} P<0.01$ as compared with age-matched control group by unpaired Student's $t$-test.

since feeding intolerance ranks as one of the most common clinical issues for preterm infants $(28,29)$, the target population for caffeine administration.

The mechanism accounting for the caffeine relaxant effect on the gastrointestinal muscle tone has been previously evaluated in adult rodent gastric tissue. The transient and localized $\mathrm{Ca}^{2+}$ release from the ryanodine receptors, best known as $\mathrm{Ca}^{2+}$ sparks, modulates muscle tone (30). Caffeine increases $\mathrm{Ca}^{2+}$ sparks and spontaneous transient outward currents, in part via ryanodine-sensitive signaling pathways resulting in the relaxation of gastric smooth muscle $(12,13)$. Phospholambaninduced phosphorylation by $\mathrm{Ca}^{2+} /$ calmodulin-dependent protein kinase II promotes sarcoplasmic reticulum $\mathrm{Ca}^{2+}$ refilling via ryanodine receptors, further contributing to the caffeine relaxant effect in fundic muscle (15). In adult guinea pigs, caffeine can also induce intestinal smooth muscle relaxation 
by facilitating the inhibitory responses to isoprenaline, cyclic 3'-5'-adenosine mono-phosphate, and papaverine (18).

Rodents are a suitable animal model to evaluate the caffeine effect on preterm neonates given that at birth their gastrointestinal function is developmentally comparable to 32 -wk gestation infants (31). In this study, we demonstrated that the caffeine-induced relaxant effect in newborn rat gastric muscle is equally dependent on ryanodine receptors.

There are limited data on the methylxanthine effect on the gastric emptying time in newborns. In a randomized control trial involving very-low-birth-weight neonates, theophylline exposure was associated with delayed gastric emptying, when compared with untreated neonates (32). To the best of our knowledge, there are no other published clinical studies where the impact of caffeine on gastrointestinal tract was assessed. The present caffeine data and literature evidence of theophyllineinduced gastric emptying delay in neonates (32), suggest that both drugs impair the infants' gastrointestinal and LES motor function.

We only evaluated the in vivo caffeine effect on gastric emptying since there are no suitable techniques to assess its impact on the intestinal transit time. Yet, our in vitro data suggest that caffeine equally lowers the intestinal muscle force potential, and this is likely to result in impaired intestinal motor function.

Finally, the extent to which the caffeine concentrations evaluated in this study reflect the therapeutic regimen in preterm neonates requires further discussion. Natarajan et al. (33) reported that caffeine blood levels in preterm infants receiving the drug varied between 3 and $24 \mathrm{mg} / \mathrm{l}$. Similar blood levels $(13 \mathrm{mg} / \mathrm{l})$ were obtained in newborn rats treated with a slightly higher caffeine dose ( $15 \mathrm{mg} / \mathrm{kg}$ gastrically) (34). These blood levels correspond to muscle bath caffeine concentrations between $10^{-5}$ and $10^{-4} \mathrm{M}$. As illustrated in Figure $3 \mathrm{~b}$, a $20-40 \%$ caffeine-induced relaxation was documented in the newborn gastric muscle following an in vitro exposure at these concentrations of the drug. Thus, the caffeine-induced effect on the newborn rat gastrointestinal and LES muscle tone in this study is within the range of therapeutic blood levels.

In summary, we showed that caffeine reduces the LES sphincter and gastrointestinal muscle tone and delays gastric emptying time in newborn rats via a mechanism involving ryanodine receptors. The caffeine effect on the human neonatal gastrointestinal motor function and its possible role in the preterm-infant feeding dysfunction warrant further study.

\section{METHODS}

\section{Chemicals and Reagents}

All chemicals and reagents were obtained from Sigma Aldrich (Oakville, ON), unless otherwise indicated.

\section{Animals}

All procedures were conducted in accordance with the Canadian Council on Animal Care regulations, and the study protocol was approved by the Hospital for Sick Children's Animal Care Committee. Sprague Dawley rats (Charles River, SAINT-CONSTANT, Quebec, Canada) bred in house were utilized. All animals were fed regular rodent pellets and housed under standard lighting and temperature conditions. The newborn rats were studied at 2-7 d of age, whereas 2-4 mo-old animals were used to obtain adult tissue. All animals were killed with an overdose of pentobarbital sodium $(60 \mathrm{mg} / \mathrm{kg}$ i.p. $)$. Immediately after death, the LES, gastric fundus, antrum, ileum, and descending colon tissue were dissected free and immediately mounted on an isometric myograph.

\section{Gastrointestinal Smooth Muscle Mechanical Response}

Longitudinally oriented gastric fundic, or circular LES, antral, ileal, and descending colon muscle strips ( $2 \mathrm{~mm}$ long and $5 \mathrm{~mm}$ wide) were studied using a modified protocol based on previous reports by others $(35,36)$. The tissue mucosa and submucosa layers were carefully removed by sharp dissection, and special care was taken to avoid any damage to the underlying muscle layer. Briefly, the tissue was maintained in an ice-cold Krebs-Henseleit solution $(\mathrm{NaCl}, 115 \mathrm{mmol} / \mathrm{l}$; $\mathrm{NaHCO}_{3}, 25 \mathrm{mmol} / \mathrm{l} ; \mathrm{NaHPO}_{4}, 1.38 \mathrm{mmol} / \mathrm{l} ; \mathrm{KCl}, 2.51 \mathrm{mmol} / \mathrm{l}$; MgSO $7 \mathrm{H}_{2} \mathrm{O}, 2.46 \mathrm{mmol} / \mathrm{l} ; \mathrm{CaCl}_{2}, 1.91 \mathrm{mmol} / \mathrm{l}$; and dextrose, 5.56 $\mathrm{mmol} / \mathrm{l}$ ) bubbled with $95 \% \mathrm{O}_{2} / 5 \% \mathrm{CO}_{2}$ until ready to be mounted on the myograph.

The muscle strips were secured at either end with $6 \times 10 \mathrm{~mm}$ flat surface tissue clips and submerged into a $10-\mathrm{ml}$ tissue bath (Radnoti LLC, Monrovia, CA) filled with the Krebs-Henseleit solution at $37^{\circ} \mathrm{C}$, $\mathrm{pH} 7.4$, and bubbled with $95 \% \mathrm{O}_{2} / 5 \% \mathrm{CO}_{2}$. One end of the muscle strip was fixed to the bottom of the tissue bath and the top clamp was tied to an isometric force transducer using 7-0 braided silk (Fine Science Tools, North Vancouver, British Columbia, Canada). The changes in force were recorded and stored digitally for processing (LabChart 7, ADInstruments, Colorado Springs, CO).

The muscle strips were equilibrated in the bath for the first $45 \mathrm{~min}$, while replacing the Krebs solution every $15 \mathrm{~min}$, and stretched to the determined optimal lengths (mean \pm SEM; fundus $=3.5 \pm 0.3$ and $4.2 \pm 0.9 \mathrm{mN}$; antrum $=2.6 \pm 0.2$ and $6.2 \pm 0.7 \mathrm{mN}$; colon $=1.5 \pm 0.1$ and $4.1 \pm 1.4 \mathrm{mN}$; ileal $=1.0 \pm 0.1 \mathrm{mN}$; LES $=2.9 \pm 0.1$ and $5.1 \pm 0.6$ $\mathrm{mN}$, for the newborn and adult, respectively). All subsequent agonist-induced force measurements were obtained at the optimal resting tension and normalized to the $\mathrm{KCl}(128 \mathrm{mmol} / \mathrm{l})$ initial response.

The muscle contraction potential was evaluated in response to carbachol $\left(10^{-6} \mathrm{M}\right)$ in the absence or presence (preincubated for $20 \mathrm{~min}$ ) of caffeine $\left(10^{-3} \mathrm{M}\right)$. To assess the caffeine-induced muscle relaxant effect, the strips were precontracted with carbachol at the concentration required to induce a $75 \%$ increase in maximal-induced force $\left(\mathrm{E}_{75}\right)$. Caffeine was subsequently added to the bath in a cumulative manner to evaluate the caffeine dose-dependent response of these precontracted muscle strips. All experiments were conducted in the presence of L-NAME (nonselective nitric oxide synthase inhibitor, $10^{-4} \mathrm{M}$ ), phentolamine (nonselective $\alpha$-adrenergic antagonist, $10^{-5}$ $\mathrm{M}$ ), and propranolol (nonselective $\beta$-adrenergic antagonist, $10^{-5}$ $\mathrm{M})$. Ryanodine $\left(10^{-5} \mathrm{M}\right)$ was utilized to evaluate the caffeine effect on the ryanodine receptors. For this, the methodology previously described by Kim et al. (15) in adult gastric tissue was employed.

\section{In vivo Measurement of Gastric Emptying Time}

The gastric emptying time was evaluated in 3-7-d-old pups. We utilized a previously described method (37), where the pups are separated from their mother at a precise time and their stomach content weighed $3 \mathrm{~h}$ later (fasting period). Normal saline (vehicle used to dissolve caffeine) or caffeine $(10 \mathrm{mg} / \mathrm{kg})$ was administered i.p. to the animals immediately after maternal separation, and they were kept in a $37^{\circ} \mathrm{C}$ environment to prevent hypothermia. The rats were killed with a barbiturate overdose and the stomach content was normalized to the pup's body weight. The dose of caffeine chosen was based on previously published reports of caffeine use in neonatal rats (38).

\section{Data Analysis}

After confirming that the data were normally distributed (skewness, kurtosis, and omnibus normality testing), the results were comparatively evaluated by unpaired or paired Student's $t$-test, as appropriate. The statistical significance was determined at $P<0.05$. All statistical analyses were performed with the Number Cruncher Statistical System software (NCSS, Kaysville, UT). Data are presented as mean \pm SEM.

\section{STATEMENT OF FINANCIAL SUPPORT}

This study was supported by a grant from the Canadian Institutes of Health Research to J.B. (MOP 93710). 
Disclosure: No conflicts of interest.

\section{REFERENCES}

1. Aranda JV, Beharry K, Valencia GB, Natarajan G, Davis J. Caffeine impact on neonatal morbidities. J Matern Fetal Neonatal Med 2010;23:Suppl 3: 20-3.

2. Sawynok J. Pharmacological rationale for the clinical use of caffeine. Drugs 1995;49:37-50.

3. Fisone G, Borgkvist A, Usiello A. Caffeine as a psychomotor stimulant: mechanism of action. Cell Mol Life Sci 2004;61:857-72.

4. Bhatt-Mehta V, Schumacher RE. Treatment of apnea of prematurity. Paediatr Drugs 2003;5:195-210.

5. Watt AH, Buss DC, Routledge PA. Effect of aminophylline on the respiratory depressant action of intravenous adenosine in neonatal rabbits. Life Sci 1987;40:29-34.

6. Aranda JV, Chemtob S, Laudignon N, Sasyniuk BI. Pharmacologic effects of theophylline in the newborn. J Allergy Clin Immunol 1986;78(4 Pt 2):773-80.

7. Fredholm BB, Bättig K, Holmén J, Nehlig A, Zvartau EE. Actions of caffeine in the brain with special reference to factors that contribute to its widespread use. Pharmacol Rev 1999;51:83-133.

8. Antonioli L, Fornai M, Colucci R, et al. Regulation of enteric functions by adenosine: pathophysiological and pharmacological implications. Pharmacol Ther 2008;120:233-53.

9. Kilbinger $\mathrm{H}$, Weihrauch TR. Drugs increasing gastrointestinal motility. Pharmacology 1982;25:61-72.

10. Faubion WA Jr, Zein NN. Gastroesophageal reflux in infants and children. Mayo Clin Proc 1998;73:166-73.

11. Skopnik H, Koch G, Heimann G. Effect of methylxanthines on periodic respiration and acid gastroesophageal reflux in newborn infants. Monatsschr Kinderheilkd 1990;138:123-7.

12. Tokutomi Y, Tokutomi N, Nishi K. The properties of ryanodine-sensitive $\mathrm{Ca}(2+)$ release in mouse gastric smooth muscle cells. Br J Pharmacol 2001;133:125-37.

13. Selemidis S, Cocks TM. Nitrergic relaxation of the mouse gastric fundus is mediated by cyclic GMP-dependent and ryanodine-sensitive mechanisms. Br J Pharmacol 2000;129:1315-22.

14. Petkov GV, Boev KK. The role of a ryanodine-sensitive $\mathrm{Ca}(2+)$-store in the regulation of smooth muscle tone of the cat gastric fundus. Gen Physiol Biophys 1998;17:225-37.

15. Kim M, Cho SY, Han IS, Koh SD, Perrino BA. CaM kinase II and phospholamban contribute to caffeine-induced relaxation of murine gastric fundus smooth muscle. Am J Physiol Cell Physiol 2005;288:C1202-10.

16. Kim M, Hennig GW, Smith TK, Perrino BA. Phospholamban knockout increases CaM kinase II activity and intracellular Ca2+ wave activity and alters contractile responses of murine gastric antrum. Am J Physiol Cell Physiol 2008;294:C432-41.

17. Pöch G, Umfahrer W. Differentiation of intestinal smooth muscle relaxation caused by drugs that inhibit phosphodiesterase. Naunyn Schmiedebergs Arch Pharmacol 1976;293:257-68.

18. Takagi K, Takayanagi I, Tsuchida Y. The effects of caffeine and imidazole on the actions of beta- and alpha-adrenergic stimulants, papaverine and cyclic 3', 5'-AMP. Jpn J Pharmacol 1972;22:403-9.

19. Goyal RK, Rattan S. Mechanism of the lower esophageal sphincter relaxation. Action of prostaglandin E 1 and theophylline. J Clin Invest 1973;52:337-41.
20. Natarajan G, Lulic-Botica M, Aranda JV. Pharmacology review clinical pharmacology of caffeine in the newborn. NeoReviews 2007;8:e214-21.

21. Wald A, Back C, Bayless TM. Effect of caffeine on the human small intestine. Gastroenterology 1976;71:738-42.

22. Tazzeo T, Bates G, Roman HN, et al. Caffeine relaxes smooth muscle through actin depolymerization. Am J Physiol Lung Cell Mol Physiol 2012;303:L334-42.

23. Dobson NR, Hunt CE. Pharmacology review: caffeine use in neonates: indications, pharmacokinetics, clinical effects, outcomes. NeoReviews 2013;14:e540-50.

24. Schmidt B, Roberts RS, Davis P, et al.; Caffeine for Apnea of Prematurity Trial Group. Caffeine therapy for apnea of prematurity. N Engl J Med 2006;354:2112-21.

25. Rivkees SA, Wendler CC. Adverse and protective influences of adenosine on the newborn and embryo: implications for preterm white matter injury and embryo protection. Pediatr Res 2011;69:271-8.

26. Scanlon JE, Chin KC, Morgan ME, Durbin GM, Hale KA, Brown SS. Caffeine or theophylline for neonatal apnoea? Arch Dis Child 1992;67(4 Spec No):425-8.

27. Boekema PJ, Samsom M, van Berge Henegouwen GP, Smout AJ. Coffee and gastrointestinal function: facts and fiction. A review. Scand J Gastroenterol Suppl 1999;230:35-9.

28. Lucchini R, Bizzarri B, Giampietro S, De Curtis M. Feeding intolerance in preterm infants. How to understand the warning signs. J Matern Fetal Neonatal Med 2011;24:Suppl 1:72-4.

29. Ng SC, Gomez JM, Rajadurai VS, Saw SM, Quak SH. Establishing enteral feeding in preterm infants with feeding intolerance: a randomized controlled study of low-dose erythromycin. J Pediatr Gastroenterol Nutr 2003;37:554-8.

30. Jaggar JH, Porter VA, Lederer WJ, Nelson MT. Calcium sparks in smooth muscle. Am J Physiol Cell Physiol 2000;278:C235-56.

31. de Vries P, Soret R, Suply E, Heloury Y, Neunlist M. Postnatal development of myenteric neurochemical phenotype and impact on neuromuscular transmission in the rat colon. Am J Physiol Gastrointest Liver Physiol 2010;299:G539-47.

32. Gounaris A, Kokori P, Varchalama L, et al. Theophylline and gastric emptying in very low birthweight neonates: a randomised controlled trial. Arch Dis Child Fetal Neonatal Ed 2004;89:F297-9.

33. Natarajan G, Botica ML, Thomas R, Aranda JV. Therapeutic drug monitoring for caffeine in preterm neonates: an unnecessary exercise? Pediatrics 2007;119:936-40.

34. Montandon G, Bairam A, Kinkead R. Long-term consequences of neonatal caffeine on ventilation, occurrence of apneas, and hypercapnic chemoreflex in male and female rats. Pediatr Res 2006;59(4 Pt 1):519-24.

35. Duman M, Ozer M, Reyhan E, et al. In vitro effect of pantoprazole on lower esophageal sphincter tone in rats. World J Gastroenterol 2011;17: 5105-9.

36. Bhetwal BP, Sanders KM, An C, Trappanese DM, Moreland RS, Perrino BA. Ca2+ sensitization pathways accessed by cholinergic neurotransmission in the murine gastric fundus. J Physiol 2013;591(Pt 12): 2971-86.

37. Lorenz DN. Gastric emptying of milk in rat pups. Am J Physiol 1985;248(6 Pt 2):R732-8.

38. Weichelt U, Cay R, Schmitz T, et al. Prevention of hyperoxia-mediated pulmonary inflammation in neonatal rats by caffeine. Eur Respir J 2013;41:966-73. 